\title{
IV. Allatizentr.
}

\section{Waldbrand = Derftcherung durch die bladbacher feuerverftcherungs= Gefellfhaft.}

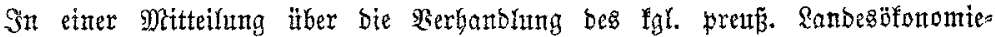
follegiunts (S. 95 bes Saltrganges 1903) war folgettbe Stelle enthnltent: "Segenitber

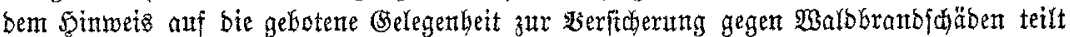

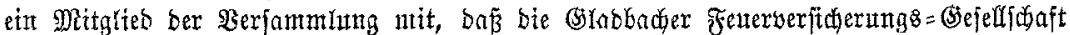

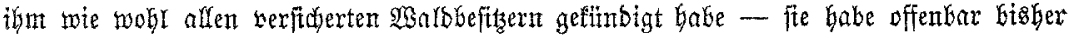

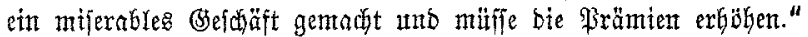

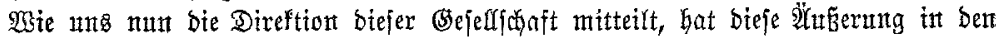

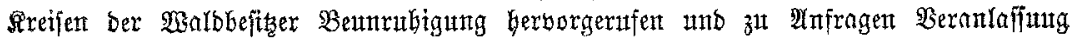
gegeben. Die Direftion müdte num bem gegenïber fonftatieren, baj bie (sejellfajaft bie Balbverftuerung na wie sor als Epezialität intenfits betreibe, wie bent auth ber

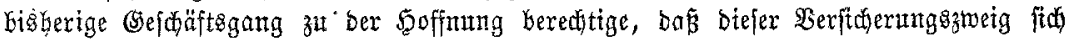

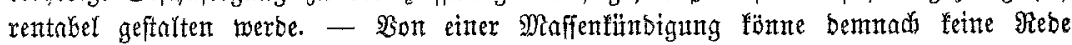

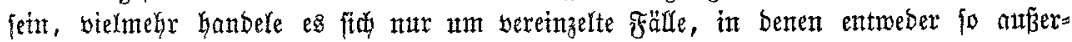

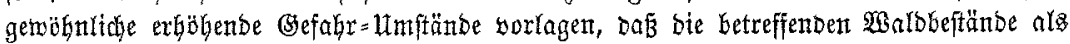
unverfiderbar angejehen werben mußten, ober um jolde Berfidyerungen, berent Betbebaltung

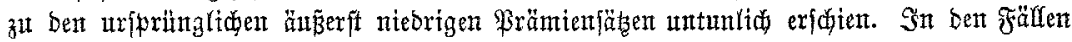

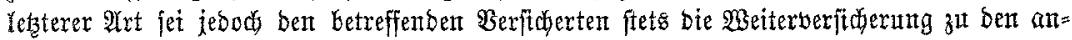
gemeffen erfühten, aber inmer noth niebrigen Präntenfäsen anbeim gegeben worben. -

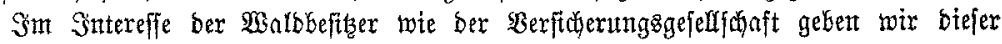
Mitteilung Der Direftion gerne Maum.

\section{feinde der Konne.}

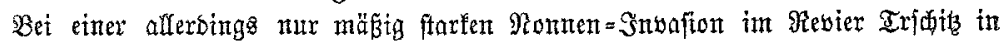


jamte Forftwejen" mitteilt, Geobahtet, baji fid verjotedene $\mathfrak{B a}$ ammanzen alo eifrige

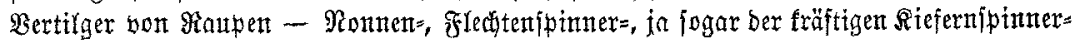

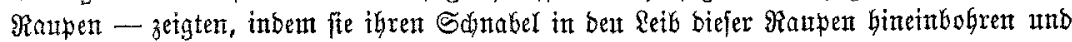

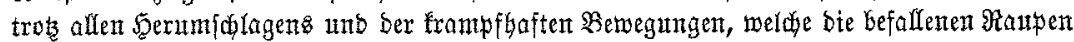

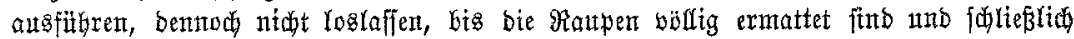

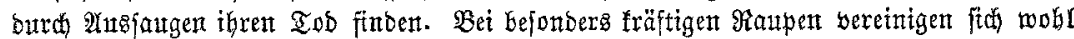

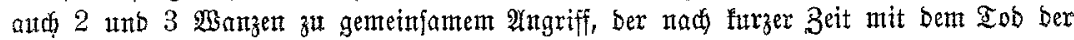
Raupe entigt.

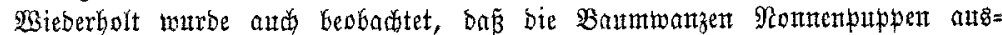

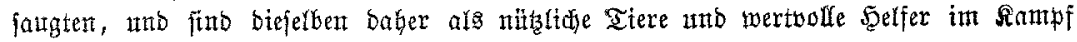




befannte Tatjadie, anb hat fid in bortiegendent Falle mieber gezeigt. Wher atth bie

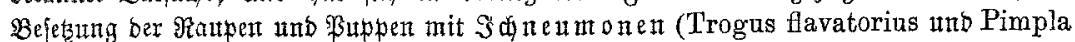

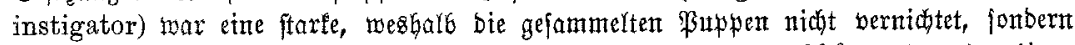

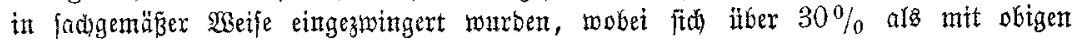

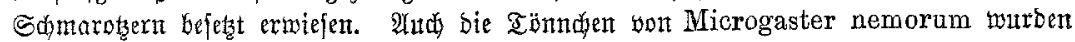
zablreid wabrgenommen.

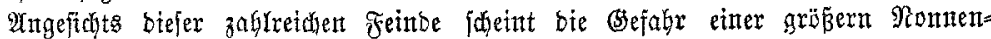
folamität in bent ßevier Iridjitz bejettigt. 